\title{
Protective Effect of Nedocromil Against Insulin Induced Airway Hyper-Reactivity
}

\author{
Mahjabeen Sharif ${ }^{1}$, Bushra Tayyaba Khan ${ }^{1}$, Ayesha Afzal' ${ }^{2}$, Fatima Qasim Malik ${ }^{3}$, Mohammad Asim Anwar ${ }^{4}$
}

\begin{abstract}
Background: Use of inhalable insulin is limited because it causes airway hyper-reactivity. So present study was designed to ameliorate inhalational insulin induced airway hyper-responsiveness.

Objectives: The objective of the study was to evaluate the acute effects of insulin on airway reactivity and protective effects of nedocromil against insulin induced airway hyper-reactivity on isolated tracheal tissues of guinea pigs in vitro. Material and Methods: This experimental study was carried out in Pharmacology department of Army Medical College Rawalpindi from January 2012 to July 2012. We observed acute effect of insulin $\left(10^{-7}-10^{-3} \mathrm{M}\right)$ and insulin pretreated with nedocromil $\left(10^{-5} \mathrm{M}\right)$ on isolated tracheal strip of guinea pig $(n=6)$ in vitro by constructing cumulative concentration response curves. The tracheal smooth muscle contractions were recorded with Transducer on Four Channel Oscillograph.

Results: Insulin significantly increased the tracheal smooth muscle contraction. The mean \pm SEM of maximum amplitudes of contraction with insulin and insulin pretreated with nedocromil were $35 \pm 1.13 \mathrm{~mm}$ and $27.8 \pm 1.27 \mathrm{~mm}$ respectively. So nedocromil significantly antagonized insulin elicited contractile effect.

Conclusion: Nedocromil significantly inhibited the insulin mediated airway hyper-reactivity in guinea pigs. So we suggest that pretreatment of inhaled insulin with nedocromil may have clinical implication in amelioration of its potential respiratory adverse effects.
\end{abstract}

Key words: Inhaled insulin, , Oscillograph, nedocromil, Tracheal muscle, Airway hyper-reactivity.

This article may be cited as: Sharif M, Khan BT,Afzal A, Malik FQ, Anwar MA

Protective effect of nedocromil against insulin induced airway hyper-reactivity. J Saidu Med Coll Swat 2020;10(2):107-110

\section{INTRODUCTION}

The predominant mode of insulin administration is by subcutaneous injection ${ }^{1}$. Injection related anxiety leads to poor compliance and suboptimal glycemic control ${ }^{2,3}$. Consequently alternative non invasive inhalational route of insulin administration was approved in $2006^{4}$. Inhalational insulin causes similar reduction in $\mathrm{HbAlc}$ and fasting blood sugar, compared with regular insulin and less risk of hypoglycemic episodes and weight gain ${ }^{5}$. It increases patient's satisfaction and improved patients compliance leading to improved glycemic control ${ }^{6,7}$. Unfortunately its use was limited due to its potential to produce respiratory adverse effects such as increased bronchial reactivity, cough, dyspnoea and bronchoconstriction ${ }^{8}$. Insulin has long been recognized as pro-inflammatory and pro-contractile hormone. ${ }^{9,10}$ The most likely mechanism of inhaled insulin induced bronchoconstriction is that insulin increases the mast cells degranulation and subsequently increased release of histamine and contractile prostaglandins are responsible for allergic inflammation of airways. ${ }^{11-13}$

\footnotetext{
1.Department of Pharmacology and Therapeutics,

Army Medical College Rawalpindi.

2.Department of Pharmacology \& Therapeutics

Wah Medical College Wah Cantt.

3.Margalla Institute of Health Sciences Rawalpindi.

4.Medical Specialist PAEC General Hospital Islamabad.
}

Correspondence: Dr. Mahjabeen Sharif Assistant Professor,

Pharmacology Department Army Medical College Rawalpindi, Pakistan Mobile No: 0333-507-7896

Email:mahjabeen30@hotmail.com

Received: April 17th,2019, Accepted: August 17th, 2020
It is well established from the review of literature that nedocromil exerts its anti-allergic and antiinflammatory effects due to its mast cell stabilizing activity ${ }^{14}$. Prophylactic use of nedocromil decreases the symptoms of air-way hyperreactivity induced by variety of allergens and chemicals ${ }^{15}$. Based on these pharmacological effects of nedocromil the present study was designed to evaluate the efficacy of nedocromil against insulin mediated airway hyper-reactivity of guinea pig in vitro.

\section{MATERIALS AND METHODS}

This laboratory based experimental study was conducted in Pharmacology department in collaboration with Centre for Research in Experimental and Applied Medicine (CREAM) Army Medical College Rawalpindi.

12 healthy guinea pigs of either sex of Dunkin Hartely variety weighing $500-700 \mathrm{~g}$ were used for current study ${ }^{16}$. These guinea pigs were randomly divided into two groups, each group consists of 6 guinea pigs. All the protocols described in this study were approved by Ethics commitee of Centre for Research in Experimental and Applied Medicine (CREAM). They were sacrificed by cervical dislocation ${ }^{17}$. The trachea was dissected out and tracheal chain was prepared with smooth muscle in the centre and cartilaginous portions on both sides. The tracheal strip was attached to the hook of oxygen tube of tissue bath containing oxygenated krebs-Henseleit solution at $37^{\circ} \mathrm{C}^{18}$. Tracheal contractions were recorded with Research Grade Isometric Force Displacement Transducer Harvard Model 
No 72-4494 on four channel oscillograph Harvard Model No $50-9307^{19,20}$.

In first group cumulative dose response curves of insulin were constructed with varying concentrations $\left(10^{-7}\right.$ to $\left.10^{-3} \mathrm{M}\right)$. When maximum response with $10^{-7} \mathrm{M}$ concentration was obtained then the subsequent doses were added without washing the previous dose ${ }^{21}$. Four channel oscillograph was used for recording tracheal muscle contraction. This group served as control group 1 and dose response curve of insulin pretreated with cromoglycate was compared with that of insulin alone.

In group 2, nedocromil was added to the organ bath in a concentration of $10^{-6} \mathrm{M}^{14}$. After 15 minutes, the successive doses of insulin ranging from $10^{-7}$ to $10^{-3} \mathrm{M}$ were added into the organ bath in the presence of nedocromil. Cumulative concentration response curves pretreated with nedocromil were constructed.

The results were expressed as Mean \pm SEM. The arithmetic means of amplitudes of contractions and SEMs were calculated using SPSS version 16. 'Student $t$ test' was used to determine the significant difference between two observations and $p$ value of less than 0.05 was considered as significant.

\section{RESULTS}

Acute effects of insulin were studied on isolated tracheal smooth muscles of guinea pig by adding the successive doses of insulin ranging from $10^{-7}$ to $10^{-3} \mathrm{M}$. Insulin induced contraction of tracheal smooth muscle was evident at a concentration of $10^{-7} \mathrm{M}$ concentration. However a significant enhancement of insulin induced contractions were observed at $10^{-5} \mathrm{M}, 10^{-4} \mathrm{M}$ and $10^{-3} \mathrm{M}$ concentration. (Figure 1).

Changes in tracheal smooth muscle contractions were measured by taking the amplitudes of tracheal smooth muscle contraction. Amplitudes of contraction with maximum dose of insulin $\left(10^{-3}\right.$ M) was $35 \pm 1.13 \mathrm{~mm}$ (Table 1). So insulin significantly enhanced the myogenic airway smooth muscle tone. This insulin induced tracheal smooth muscle contraction was significantly reduced in nedocromil treated group from $35 \pm$ $1.13 \mathrm{~mm}$ to $14.55 \pm 0.62 \mathrm{~mm}$. The means of amplitudes of contractions with varying doses of insulin when compared between group 1 and 2 were found to be statistically significant (Table 1). Our data showed that maximum constrictor response of insulin in the presence of nedocromil was reduced by 41.57 percent as compared with insulin group (Table 1). Insulin concentration response curve in the presence of nedocromil was shifted to the right and downwards indicating a profound inhibitory effect of nedocromil sodium on airway hyper-reactivity induced by insulin (Figure 1).

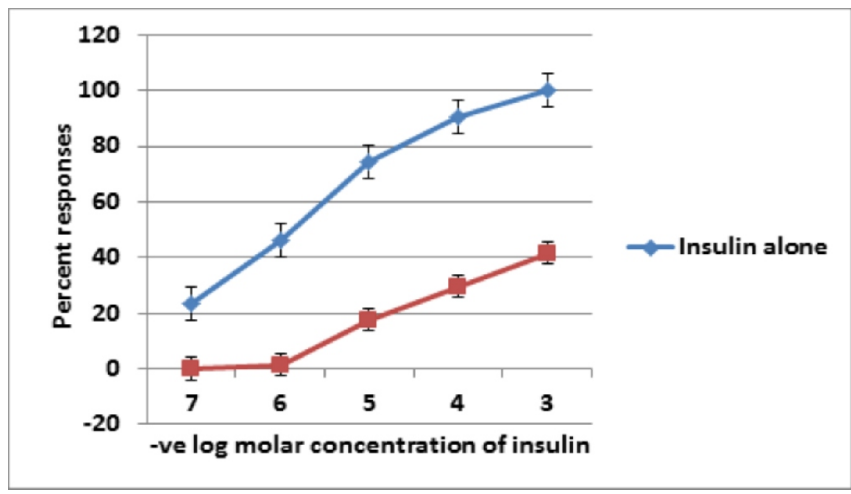

Figure 1: Comparison of semi log concentration response curve of group 1 (insulin control) and group 2 (insulin after pretreatment with nedocromil) on isolated tracheal smooth muscle of guinea pig.

Table 1: Comparison of responses of isolated tracheal muscle of guinea pig between insulin (group 1) and insulin pretreated with nedocromil (group 2).

\begin{tabular}{|c|c|c|c|c|c|}
\hline $\begin{array}{c}\text { Concentration } \\
\text { of insulin (M) }\end{array}$ & $\begin{array}{c}\text { Amplitude of } \\
\text { contraction } \\
\text { with insulin } \\
\text { (mean } \pm \\
\text { S.E.M) } \\
(\mathbf{m m}) \mathbf{n = 6}\end{array}$ & $\begin{array}{c}\text { Amplitude of } \\
\text { contraction } \\
\text { with insulin } \\
\text { pretreated with } \\
\text { nedocromil (mean } \\
\text { S.E.M) }(\mathbf{m m}) \mathbf{n = 6}\end{array}$ & $\begin{array}{c}\text { p-value } \\
\text { between } \\
\text { group 1\&2 }\end{array}$ & $\begin{array}{c}\text { Percent } \\
\text { response } \\
\text { with } \\
\text { insulin }\end{array}$ & $\begin{array}{c}\text { Percent } \\
\text { response } \\
\text { with insulin } \\
\text { pretreated } \\
\text { with } \\
\text { nedocromil }\end{array}$ \\
\hline $10^{-7}$ & $8.167 \pm 2.14$ & $0 \pm 0$ & $.004^{*}$ & 23.34 & 0 \\
\hline $10^{-6}$ & $16.16 \pm 2.48$ & $0.5 \pm 0.837$ & $.007^{*}$ & 46.17 & 1.43 \\
\hline $10^{-5}$ & $26.1 \pm 2.78$ & $6.17 \pm 1.169$ & $0.000^{*}$ & 74.58 & 17.62 \\
\hline $10^{-4}$ & $31.8 \pm 2.04$ & $10.33 \pm 1.63$ & $.003^{*}$ & 90.86 & 29.5 \\
\hline $10^{-3}$ & $35 \pm 2.76$ & $14.55 \pm 1.52$ & $.004^{*}$ & 100 & 41.57 \\
\hline
\end{tabular}

$p$ value $<0.05=$ Significant $\left({ }^{*}\right)$ 


\section{DISCUSSION}

The present study demonstrated that insulin induced airway smooth muscle contraction of guinea pigs in a concentration range of $10^{-7} \mathrm{M}$ to $10^{-3} \mathrm{M}$. These contractions were reversible and sustained in nature. Schaafsma et al also reported the acute contractile effect of insulin on isolated tracheal preparation of guinea pig but the concentration of insulin used was in the range of $10^{-10}$ to $10^{-5} \mathrm{M}^{21}$. Our observations are also supported by in vivo studies in which treatment of diabetic rats with insulin resulted in airway hyperreactivity and inflammation. This enhanced airway reactivity was due to the release of inflammatory mediators from mast cells under the influence of insulin $^{22}$. Our findings are also in accordance with clinical observations in which airway responsiveness was increased in patients with type II diabetes during first three months of insulin therapy. In another study intratracheal instillation of insulin loaded nanoparticles increased the inflammatory response of human airways. Futhermore it has been demonstrated that insulin might be required for development of initial events of asthmatic reactions ${ }^{23}$.

When isolated tracheal muscle was pretreated with nedocromil, the maximum percent response of insulin in the presence of nedocromil was reduced to 41.57 percent of insulin control. The mean values of amplitudes of contractions and mean percent responses when compared between two groups, were found to be statistically significant. Nedocromil caused a downward and rightward shift of concentration response curve. The concentration response curves obtained with nedocromil were compared to curves of insulin. It was observed that nedocromil significantly ameliorated the insulin mediated airway hyperreactivity. Since insulin is a pro-inflammatory and pro-contractile hormone. The protection offered by nedocromil is presumably through the inhibition of release of contractile prostaglandins and histamine from mast cells of isolated tracheal strip. To our knowledge this is the first study which revealed protective effect of nedocromil against insulin induced airway contraction. Our results are in accordance with other studies in which nedocromil has been shown to inhibit the bronchoconstrictor response to several kinds of challenges. Our observations are in agreement with results of a study conducted on cannine tracheal smooth muscle which revealed that nedocromil inhibited voltage dependent $\mathrm{Ca}^{++}$and $\mathrm{Ca}^{++}$dependent $\mathrm{Cl}^{-}$current in airway smooth muscles and caused relaxation of tracheal smooth muscles ${ }^{24}$. This study provides us a clue that nedocromil can attenuate the pro-contractile effect of insulin. So we suggest that pretreatment with nedocromil may ameliorate respiratory adverse effects of inhaled insulin therapy in diabetic patients. But further clinical trials are warranted to confirm whether the protection offered by nedocromil in guinea pig model can translate to human airways.

\section{CONCLUSION}

Insulin induces airway smooth muscle contraction which was significantly inhibited in the presence of nedocromil. So nedocromil can become useful therapeutic agent for attenuation of insulin induced airway hyper-reactivity.

\section{REFERENCES}

1. Parkner ZM, Frystyk J, Laursen $T$, Lauritzen $T$, Christiansen JS. A comparison of pharmacokinetic and pharmacodynamics of insulin Aspart, Biphasic insulin Aspart 70, Biphasic insulin Aspart 50, and human insulin A randomized, Quadruple crossover study. Diabetes Technol Ther. 2012; 51: 78-87.

2. Shlomowitz A, Feher DM. Anxiety associated with self monitoring of capillary blood glucose. $\mathrm{Br} \mathrm{J}$ Diabetes. 2015; 14(2): 92-99.

3. Pettus J, Santos Cavaiola T, Edelman SV. Recommendations for initiating use of Afrezza inhaled insulin in individuals with type 1 diabetes. Diabetes technology \& therapeutics. 2018; 20(6):448-451.

4. Yaturu S. Insulin therapies: current and future trends at dawn. World J of diabetes. 2013 4(1):144-149.

5. Guadiana DG, Romualdo L, Morales G, Oton A, Garcia M, Gonzalez OM. (2012). The value of hemoglobin A1c for diagnosis of diabetes mellitus and other changes in carbohydrate metabolism in women with recent gestational diabetes mellitus. Endocrinol Nut 2012; 120 : 90-101.

6. Heinemann L, Baughman R, Boss A, Hompesch $M$. Pharmacokinetic and pharmacodynamic properties of a novel inhaled insulin. Journal of diabetes science and technology. 2017; 11(1):148-156.

7. Shah RB, Patel M, Maahs DM, Shah VN. Insulin delivery methods: Past, present and future. International journal of pharmaceutical investigation. $2016 ; 6(1): 221-229$.

8. McGill JB, Ahn D, Edelman SV, Kilpatrick CR, Cavaiola TS. Making insulin accessible: does inhaled insulin fill an unmet need?. Advances in therapy. 2016; 33(8):12671278.

9. Ma YL, He QY. Study of the role of insulin and insulin receptors in allergic airway inflammation of rats. Zhonghua Yi Xue Za Zhi. 2005; 85 : 3419-24.

10. Kolahian S, Asadi F, Nassiri MS. Reduced inflammatory parameters in airways of diabetic-antigen sensitized guinea pigs. Domestic Animal Endocrinology 2011; 42 (10): 13-22.

11. Dasgupta P, Dorsey NJ, Li J, Qi X, Smith EP, YamajiKegan K, Keegan AD. Insulin receptor substrate (IRS)-2 negatively regulates alternative macrophage activation and allergic lung inflammation. Science signaling. 2016; 21(13):63-70. 
12. Martin JO, Campos AC, Cruz WJ, Manzolli S, Alves AV Vianna $E$. Insulin modulates cytokine release and selectin expression in the early phase of allergic airway inflammation in diabetic rats. BMC 2010; 10 (3): 39-46.

13. Dekkers GB, Bos TS, Zaagsma J, Meurs H. Functional consequences of human airway smooth muscle phenotype plasticity. Br J. Pharmacol 2012; 166 (1): 359-67.

14. Andersson C, Tufvesson E, Diamant Z, Bjermer L. Revisiting the role of the mast cell in asthma. Current opinion in pulmonary medicine. 2016; 22(1):10-17.

15. Douglas $W$, Hay $P$. Pharmacology of leukotriene receptor antagonist. Chest 2012; 111:35-45.

16. Boskabady $\mathrm{MH}$, Hashemzehi M, Khazdair MR, Askari VR. Hydro-ethanolic extract of Portulaca oleracea affects beta-adrenoceptors of guinea pig tracheal smooth muscle. IJPR. 2016;15(4):867-871.

17. Albuquerque AA, Carvalho MT, Evora PM, De Nadai TR, Celotto AC, Evora PR. In vitro reactivity ("organ chamber") of guinea pig tracheal ringsmethodology considerations. Annals of translational medicine. 2016 ; 40 (11) 45-53.

18. Al-Ayed MS. Relaxant effect of ghrelin on guinea pig isolated tracheal smooth muscle: role of epithelial NO and PGE 2. EJP. 2018; 470 (6):949-958.

19. Dekkers GB, Schaafsma D, Tran T, Zaagsma J Meurs $\mathrm{H}$. Insulin-induced laminin expression promotes a hypercontractile airway smooth muscle phenotype. Am. J. Respir. Cell Mol. Biol 2009; 41 : 494-504.

20. Shakeri F, Roshan NM, Kaveh M, Eftekhar N, Boskabady $\mathrm{MH}$. Curcumin affects tracheal responsiveness and lung pathology in asthmatic rats. Pharmacological Reports.2018; 70(5):981-987.
21. Ferreira SS, Nunes FP, Casagrande FB, Martins JO. insulin Modulates cytokine release, collagen and Mucus secretion in lung remo deling of alle rgic Diabetic Mice. Frontiers in immunology. 2017; 8:633-639.

22. Machado CS, Lima TW, Damazo SA, Carralho FV, Martins AM, Silva RM, et al. Down regulation of mast cell activation and airway reactivity in diabetic rats: role of insulin. ERJ 2004; 24 (4): 552-58.

23. Parameswaran $P K$, Bodas $M$, Singh $S$, Freeman MR, Thompson MA, Bhatraju N, etal. Airway epithelium: Molecular regulation of inflammation: Insulin Mediated Airway Remodeling Via [Beta] Catenin Signaling. American J of Resp and Critical Care Medicine. 2016; 17(3):193:199.

24. Ramzan M, Iqbal N, Karim A. Effect of Beclomethasone Dipropionate Versus Mast Cell Stabilizer on Mucociliary Clearance in Patients of Allergic Rhinitis. JIMDC. 2018; 7(2):92-96. 